\title{
SEMBLANZA:
}

\section{EL OFICIO DE ESCRITORA DE JULIETA PINTO GONZÁLEZ}

\author{
Semblance: \\ The charge of writer of Julieta Pinto González. \\ Irene González Muñoz*
}

\begin{abstract}
RESUMEN
El siguiente texto presenta una breve semblanza de la cuentista costarricense Julieta Pinto González. Palabras clave: literatura hispanoamericana, cuentos costarricenses, Julieta Pinto González.
\end{abstract}

\begin{abstract}
The following text presents a brief history of the Costa Rican story writer Julieta Pinto González.

Key Words: American literature, Costa Rican stories, Julieta Pinto Gonzalez.
\end{abstract}

* Universidad de Costa Rica. Profesora Departamento de Literatura. Escuela de Filología, Lingüística y Literatura. Costa Rica.

Correo electrónico: irenego123@gmail.com

Recepción: 18/3/2016. Aceptación: 3/8/2016. 
La escritora y educadora, Julieta Pinto González, nace el 31 de julio de 1922. Su niñez transcurre en San Rafael de Alajuela. Cursa sus estudios primarios en la Escuela República del Perú y los secundarios en el Colegio Superior de Señoritas. En el año 1971 obtiene el grado de Licenciada en Filología, Lingüística y Literatura, en la Universidad de Costa Rica, con la tesis "Relación paisaje-personaje en la novela Pedro Páramo". Posteriormente, viaja a Francia donde realiza estudios en Sociología de la Literatura.

Motivada por sus preocupaciones sociales, ocupó varios cargos en la vida pública del país, en instituciones como el Instituto Mixto de Ayuda Social y el Instituto de Tierras y Colonización. En el ámbito educativo fue fundadora y directora de la Escuela de Literatura y Ciencias del Lenguaje de Universidad Nacional. En 1996 es distinguida con el Premio Nacional de Cultura Magón y ocupó de 1992 a 2012 la silla N de la Academia Costarricense de la Lengua.

$\mathrm{Su}$ producción literaria es extensa y variada. Se inicia con Cuentos de la Tierra (1963), cuando siendo aún estudiante de filología, es motivada por su profesor y mentor, Isaac Felipe Azofeifa, a escribir literatura, según ella misma lo ha señalado en diversas entrevistas. En 1967 publica Si se oyera el silencio; en 1969, La estación que sigue al verano (Premio Nacional Aquileo J. Echeverría); en 1970 publica Los marginados (por el cual también recibe el Premio Nacional Aquileo J. Echeverría), continúa con A la vuelta de la esquina (1975), El sermón de lo cotidiano (1977), El eco de los pasos (1979), David (cuentos infantiles) es publicado también en 1979, Abrir los ojos (poesía, 1982), La lagartija de la panza color musgo (1986), Entre el sol y la neblina (1987), Historia de navidad (cuentos infantiles) de 1988, Tierra de espejismos (1991), El despertar de Lázaro se publica en 1994 (Premio Nacional Aquileo J. Echeverría), El lenguaje de la lluvia (2001), El niño que vivía en dos casas (cuento infantil, 2002), Detrás del espejo (2000), Tata Pinto (2005), Pizco (2008),y El Laberinto del recuerdo del 2010.

En su ya mencionada tesis de licenciatura, "Relación paisaje-personaje en la novela Pedro
Páramo", realiza un riguroso y pormenorizado estudio sobre el paisaje en esta novela desde la perspectiva del círculo filológico de Leo Spitzer; es decir, emplea un método estructuralista, al que suma, además, un método histórico para demostrar que el paisaje se relaciona con la estructura, con la acción y con los personajes de Pedro Páramo. Precisamente, en la introducción a este estudio, Julieta Pinto afirma lo siguiente en relación con el oficio del escritor:

la literatura como fenómeno social no puede
circunscribirse a límites nacionales, sino al ámbito
regional hispanoamericano; pero, al mismo tiempo,
no puede separarse de los problemas internos de sus
propios países. Al rebasar la literatura los límites
regionales y locales se vierte en el hombre como
factor principal de su preocupación, el hombre y
todos los problemas que le conciernen. Así pues, la
literatura no sirve ahora de simple entretenimiento,
sino que da a conocer problemas que el escritor
desea que se conozcan (Pinto 1971: 6).

Estas palabras, coinciden cabalmente con el ejercicio de escritura de la propia Julieta Pinto, sobre todo, en esa preocupación por dar a conocer al hombre y sus problemas. En este sentido, baste recurrir a la clasificación planteada por Álvaro Quesada Soto, quien ubica la obra de esta autora en el grupo de escritores de la "Segunda República", que se inicia en la década de 1950.

De acuerdo con Quesada (2008) tras la guerra civil de 1948, y debido al advenimiento de un nuevo proyecto nacionalista y un nuevo periodo modernizador, se generaron en el país una serie de reformas, cuya finalidad se centraba no sólo en mejorar las condiciones socio-económicas, sino también en el afán de progreso. Así, entre otras medidas, se nacionalizó la banca, se crearon instituciones públicas encargadas de la expansión de la salud, de la educación y de la cultura, como también se crearon otras destinadas a la mejora de la infraestructura en las vías de comunicación y de otros servicios públicos (electricidad y telefonía, por ejemplo). No obstante, este panorama de desarrollo, también generó otros problemas como el endeudamiento y la dependencia de gobiernos extranjeros, 
la entronización del aparato burocrático, las migraciones del campo a la ciudad, el crecimiento desmedido y descontrolado del área metropolitana y los consecuentes problemas sociales de estos movimientos.

Ante este panorama los escritores de la "Segunda República", centran su producción en una vertiente realista de denuncia o de indagación social de los efectos causados por este nuevo proyecto modernizador. De esta manera, temáticas como el desarrollo histórico del país, la preocupación por el ambiente, la corrupción política y la traición a los ideales de la socialdemocracia se abordan en la literatura de este periodo.

Acorde con lo anteriormente planteado, en la producción narrativa de Julieta Pinto, tenemos por primera vez en letras costarricenses un abordaje novedoso de la naturaleza, concretamente en su primera publicación, Cuentos de la Tierra (1963), pues en los dieciséis relatos que conforman el texto se desarrolla la temática ambiental desde una perspectiva clara e intencionadamente ecológica, esto lo consigue al centrar la trama de los relatos en la relación ser humano/naturaleza. Por ejemplo, en el cuento "El volcán" se critica la insensibilidad del hombre moderno que no respeta ni teme a las fuerzas de la naturaleza como lo hacía el hombre de antaño. En "La tierra estéril" se plantea que si la relación ser humano/naturaleza es amorosa, la tierra responde generosamente. En "El espíritu del Bosque" se describe la destrucción del espacio paradisiaco del bosque en aras del deseado progreso.

En Si se oyera el silencio (2005), la importancia de las historias narradas se concentra en las experiencias de vida de varias parejas desde la perspectiva íntima de los personajes femeninos, cuya característica en común, además de ser mujeres, es el haber sido silenciadas por la cultura hegemónica.

En El eco de los pasos, aborda a través de los recuerdos de Ernesto, el protagonista, los ideales del grupo opositor al gobierno durante la guerra civil de 1948, y cómo este personaje siente que, a veinticinco años del enfrentamiento, los ideales fueron traicionados, sobre todo, cuando no consigue la ayuda de las autoridades políticas (antiguos compañeros revolucionarios) para liberar a Carlos, el guerrillero del país del norte, que se encuentra encarcelado y cuyo único deseo es continuar en su lucha. Ante esta situación, Ernesto afirma:

He pretendido hallar apoyo, comprensión, para
un movimiento libertador como el que una vez
tuvimos en nuestras manos. Y lo he pretendido,
porque sin decírmelo, todavía tenía la esperanza de
encontrar el eco de otros tiempos, y el eco de otros
pasos (Pinto 2005: 118).

En El sermón de lo cotidiano (1995), novela de corte existencial que muestra la incomunicación entre los seres humanos; conocemos a Silvia, la mujer que fue silenciada desde su infancia hasta su edad adulta, lo cual le genera problemas sicológicos; y a Pepe, quien fue prácticamente obligado por sus padres a convertirse en sacerdote y quien muestra serios problemas en cuanto a su vocación. Lo interesante de esta historia es que el encuentro de estos personajes es en un centro de salud, donde los ayudan a superar sus conflictos personales.

Por último, pues más adelante escucharemos más diversas y detalladas propuestas de lectura de los ponentes de este coloquio en torno a la producción escritural de Julieta Pinto, sólo me queda señalar su interés por los lectores infantiles a quienes también dirige parte de su producción con textos como David, El niño que vivía en dos casas y los mismos Cuentos de la tierra (relatos que dedica a su propio hijo), así como también demuestra una dimensión afectiva en su ejercicio de escritura y que se evidencia en Pizco (2008), relato en el que nos narra las aventuras y vicisitudes de Pizco, y la relación entre esta mascota y su ama, les leo el primer párrafo de este relato: “ Pizco nació pequeño y húmedo como todos los perros. Gimió cuando lo separaron de la madre como todos los perros. Como ellos bebió leche, y se acurrucó en mi regazo para dormir tranquilo (Pinto 2008: 1)".

Como vemos, desde una aproximación panorámica, Julieta Pinto ha sido fiel a su oficio de escritora, pues su principal preocupación 
ha sido escribir sobre el hombre y todos los problemas que le conciernen, tarea a la que se ha abocado con plena conciencia y, aunque su producción textual, como toda práctica cultural generada por un sujeto socio-histórico, es susceptible a otros abordajes de lectura, es innegable que en el caso de esta autora se cumple su intención por representar al "hombre y los problemas que le conciernen", como lo deja claro en la introducción a su tesis de licenciatura, esto con el afán, tal y como lo propone Herodoto, a quien cita en uno de los epígrafes del paratexto de El eco de los pasos: "Para que las acciones de los hombres no caigan con el tiempo en el olvido".

\section{Bibliografía}

Pinto González, Julieta. (1963). Cuentos de la tierra. San José: L'Atelier.
Pinto González, Julieta. (2005). El eco de los pasos. San José: Editorial Universidad Estatal a Distancia.

Pinto González, Julieta. (1995). El sermón de lo cotidiano. San José: Editorial Universidad Estatal a Distancia.

Pinto González, Julieta. (2008). Pizco. San José: Editorial Universidad Estatal a Distancia.

Pinto González, Julieta. (2005). Si se oyera el silencio. San José: Editorial Costa Rica.

Pinto González, Julieta. (1971). Relación paisajepersonaje en la novela Pedro Páramo. Tesis de Licenciatura. Universidad de Costa Rica.

Quesada Soto, Álvaro. (2008). Breve historia de la literatura costarricense. San José: Editorial Costa Rica.

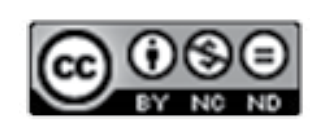

Este obra está bajo una licencia de Creative Commons Reconocimiento-NoComercial-SinObraDerivada 4.0 Internacional. 